\title{
Epidemiological and clinical differences of snake bites among children and adults in south western Saudi Arabia
}

\author{
Naffaa Al Harbi
}

\begin{abstract}
Objectives-To compare the clinical course and complications of snake bite in children and adults.

Methods-A retrospective review of 66 patients ( 28 children and 38 adults) admitted after snake bites for management at the Prince Abdullah Hospital in Bisha, in the south western part of Saudi Arabia, during the period May 1992 to May 1995.

Results-No significant difference was found in time of bite, site of bite, and sex preference between adults and children. Local complications, such as tissue necrosis, were commoner in children (14\%) than in adults (5\%). Systemic manifestations were also more commonly seen in children than in adults; this is possibly due to a higher ratio of injected venom to body mass in children. Leukocytosis was seen in $54 \%$ of children (adults 13\%), a low haemoglobin concentration in $14 \%$ of children (adults 11\%), prolonged prothrombin and partial thromboplastin times in $41 \%$ of children (adults 16\%), while a high creatine phosphokinase was seen in $31 \%$ of children compared with $17 \%$ of adults.

Conclusions-Children seem to have more serious local and systemic complications than adults and this may indicate the need to use a higher dose of antivenom than that being used at present. ( $₹$ Accid Emerg Med 1999;16:428-430)
\end{abstract}

Keywords: snake bites; Saudi Arabia

Snake bite is a common problem in the south western part of Saudi Arabia where seven out of every 1000 patients who visited the emergency room over a three year period had sustained a snake bite. This constitutes $2.4 \%$ of all admissions during the hot season when snakes commonly inflict bites. We believe the occurrence of snake bite in this area is in fact higher because some cases are probably treated at a primary health care centre or by a local healer and do not come to hospital or may not seek any help.

Surveys of the region and other reports indicate that most snake bites are from carpet vipers. ${ }^{1-3}$ Other types described are the Arabian cobra (Naja haje arabica) and the burrowing snake (Atractapsis microlepidoita). This retrospective study discovered that the patient record did not give a good description of the snake. The snake is frequently not seen by the patient, especially by a child or at night. While adults seem to be the victims more often than children, ${ }^{4}$ children have been thought to present with more complications, presumably due to injection of more snake venom in relation to body mass. ${ }^{25}$ Although there have been few reports on snake bites in adults (with a few children mentioned in some), there has been only one report of snake bite complications in children from this region. ${ }^{1}$ This study, therefore, was carried out to highlight the importance of snake bites among children and adults and to compare the clinical course and complications in the two groups.

\section{Patients and methods}

Records of all cases of confirmed snake bites admitted to the Prince Abdullah Hospital in Bisha (south western Saudi Arabia) from May 1992 to May 1995 were reviewed. Snake bite was confirmed in all cases by description of the attack or the presence of bite marks of snake fangs. The following data were extracted: age, sex, bite site, bite time, interval between time of snake bite and arrival in the hospital, symptoms, signs, heart rate, blood pressure, and duration of stay in hospital. Laboratory results reviewed included complete blood count, prothrombin and partial thromboplastin time, highest serum creatinine concentration during stay in hospital, and creatine phosphokinase level. All these tests were done when the patients reached the emergency room.

Data of children 12 years of age and below (this is the age limit for admission of children into the paediatric ward in the hospital) were compared with those of patients above this age group (referred to as adults).

Standard treatment with polyvalent snake antivenom was given intravenously to all patients who had evidence of a snake bite (equine polyvalent immune serum, antisnake serum for the near Middle East; Behring, Marburg, Germany). The dose used for children was $20-50 \mathrm{ml}$, mean $30 \mathrm{ml}$, and for adults 30-110 ml, mean $50 \mathrm{ml}$. Cellulitis was treated with ampicillin and/or methicillin or another antistaphylococcal agent. Parenteral hydrocortisone was given for cases with a positive skin test to snake antivenom. Paracetamol or diclofenac were given as analgesics where indicated.

\section{Results}

A total of 66 patients were admitted with a confirmed diagnosis of snake bite during the study period. This constitutes seven of every 
Table 1 Systemic manifestaitons and local complications of snake bites in children and adults

\begin{tabular}{lll}
\hline & $\begin{array}{l}\text { Group I } \\
\text { (children, } \\
\leqslant 12 \text { years, \%) }\end{array}$ & $\begin{array}{l}\text { Group II } \\
\text { (adults, } \\
>12 \text { years, \%) }\end{array}$ \\
\hline Leukocytosis $\left(>12 \times 10^{9} / 1\right)$ & $54(15 / 28)$ & $13(5 / 38)$ \\
Haemoglobin $\leqslant 120 \mathrm{~g} / 1$ & $14(4 / 28)$ & $11(4 / 38)$ \\
Prolonged PT and/or PTT & $41(11 / 27)$ & $16(6 / 38)$ \\
High CPK (>200 U/1) & $31(4 / 13)$ & $17(5 / 30)$ \\
Local tissue necrosis & $14(4 / 28)$ & $5(2 / 38)$ \\
Local swelling & $46(13 / 28)$ & $53(20 / 38)$
\end{tabular}

$\mathrm{CPK}=$ creatine phosphokinase $\mathrm{PT}=$ prothrombin time; $\mathrm{PTT}$ $=$ partial thromboplastin time.

1000 patients who visited the emergency room and $2.4 \%$ of admissions during the hot season when most cases were seen. The 66 patients admitted were 28 children (range 1.5-12 years, mean age 7.6 years) and 38 patients older than 12 years (range 14-80 years, mean age 34.4 years). There were 18 male and 10 female children (sex ratio 1.8:1) compared with 30 male and eight female adults (sex ratio 3.8:1). More bites took place in the day time: 15 children $(54 \%)$ and 20 adults $(57 \%)$. In three of the adults we could not discover an accurate time of bite from the records. Most bites occurred during May to September. Bites on the lower limbs occurred in 20 children (74\%) compared with 25 adults $(66 \%)$, while bites in the upper limbs occurred in seven children (26\%) and 13 adults (34\%); in one child we could not locate the site of bite.

The mean interval between the snake bite and arrival at hospital was three hours for children and seven hours for adults. Children stayed a mean of four days in hospital and adults five days. Vital signs, including blood pressure, were normal in all patients, but one 6 year old child had unrecordable blood pressure on arrival in our emergency room. Systemic and local manifestations are summarised in table 1.

Necrosis at the site of bite occurred in four (14\%) children compared with two (5\%) adults. All these patients required fasciotomy and intervention by a plastic surgeon. Local pain at the site of the bite was reported in all cases of snake bite. Swelling was, however, found less often in children than in adults: 13 (46\%) compared with 20 (53\%).

A prolonged prothrombin time and partial thromboplastin time were more often found in children; the times were prolonged in 11 out of 27 children $(41 \%)$ tested compared with six out of 38 adults $(16 \%)$ tested $(p<0.05)$. The prothrombin time was defined as prolonged if it was more than three seconds above the control and above the normal range (11-15 seconds). The partial thromboplastin time was defined as prolonged if it was more than 10 seconds above the control and above the normal range (25-40 seconds). Leukocytosis $\left(>12 \times 10^{9} / 1\right)$ was also more frequent in children: 15 (54\%) children compared with five $(13 \%)$ adults $(p<0.05)$. A low haemoglobin concentration $(\leqslant 120 \mathrm{~g} / \mathrm{l})$ was seen in four $(14 \%)$ children and four $(11 \%)$ adults but the difference was not significant $(p>0.05)$. High creatine phosphokinase $(>200 \mathrm{U} / \mathrm{l})$ was more frequently found in children $(4 / 13,31 \%)$ than in adults $(5 / 30,17 \%)$ but again the difference was not significant $(p>0.05)$. Serum creatinine was within the normal range in all cases. There was no mortality. All of our patients were discharged home with no permanent disability.

\section{Discussion}

There were more adults (58\%) than children with snake bites; this has been reported in other studies. ${ }^{46}$ This is likely to be due to occupational hazards as some of the men in this area are farmers. The same reason would seem to explain why men are more commonly bitten than women (ratio 3.8:1). Boys are allowed to play outside more than girls and are more often victims of snake bites. The male:female ratio in children was 1.8:1. Daytime bites were only slightly higher than night or evening time bites, 15:13 in children and 20:15 in adults. While the risk of daytime bites is higher, the prevalence of night time bites is still relatively high. This could be due to custom in Saudi Arabia: people spend their evenings sitting and eating outside on the ground, enjoying the natural evening breeze, and often sleeping on the ground. As snakes are more active during spring and summer, most of our patients were bitten during the hot season, and this is similar to the findings in other studies. ${ }^{25}$ The lower limbs are the commonest site of bites in both children (74\%) and in adults $(66 \%)$. They are obviously more easily accessible, especially when walking barefoot. ${ }^{1}{ }^{26-8}$

This study shows that children are brought to the hospital within a shorter mean interval (three hours) after a snake bite than adults (seven hours) in our region. Annobil reported a mean of six hours for children ${ }^{1}$ and Malik reported 9.8 hours for adults ${ }^{2}$; this could be explained by the fact that adults are able to endure pain more than children and in any case are more worried when their children are affected. The interval is, however, relatively long for both groups. This could be explained by the geographical size and often mountainous terrain in this area with a long travel time to the health centres. Fortunately there were no deaths in either group, although the mortality ranged from $2 \%$ to $7.7 \%$ of affected children in other reports. ${ }^{8-10}$ This could be because of different snake types and availability of polyvalent antivenom in nearby primary health care centres and hospitals.

Systemic envenomation effect was more apparent in children than in adults. For example, prolonged prothrombin and partial thromboplastin time were more commonly observed in children (41\%) than in adults (16\%). Leukocytosis was seen in $54 \%$ of children compared with $13 \%$ of adults, while a low haemoglobin concentration was present in $14 \%$ of children compared with $11 \%$ of adults. Also a high creatine phosphokinase, due apparently to rhabdomyolysis caused by snake venom, was more frequent in children $(31 \%)$ than in adults $(17 \%)$. Renal failure, which is thought to be due to fibrin deposits in the glomerular capillaries or direct nephrotoxic effect, ${ }^{11}$ and has been described in children 
more than adults, ${ }^{12}$ was not observed in our study in either group. The severe systemic manifestations in children would, however, put this group of children at risk of renal failure. The reason for the more evident systemic response observed in children might be due to the higher dose of venom per unit body mass, assuming that the amount of venom injected is the same in adults and children so that the relative concentration of venom achieved in plasma of children is higher.

All these tests were done when the patients arrived at the emergency room, although the mean time of arrival was seven hours for adults and three hours for children. We doubt if this is the reason for the discrepancy in the results because in children and adults who arrived within four hours of the bite, prothrombin time and partial thromboplastin time were prolonged in $33 \%$ and $12 \%$ respectively.

In conclusion, this study confirms that snake bite is a common problem in both adults and children in this area of Saudi Arabia. Adult males are more often the victims than children and females. Children are brought more quickly after a snake bite than adults, although the time interval of three hours remains relatively long. Signs of systemic envenomation are more serious in children than in adults. This might suggest that a higher dose (than previously used) of snake antivenom would be necessary in children in the management of snake bites. People should be strongly advised to wear shoes, especially when outdoors, and avoid sleeping on the ground. The epidemiology of snake bites would be improved if all clinics and emergency rooms had snake specimens or pictures to show the patient for identification purposes when the snake has been seen or caught.

Conflict of interest: none.

Funding: none.

1 Annobil SH. Complications of Echis colorata snake bites in Asir region of Saudi Arabia. Ann Trop Paediatr 1993;13:3944.

2 Malik GM. Snake bites in adults from the Asir region of southwestern Saudi Arabia. Am f Trop Med Hyg 1995;52: 314-17.

3 Mohan KN. Snake bite in the Middle-East. Postgraduate Doctor (Middle East) 1988;11:24-6.

4 Al-Mohareb F, Al-Sadoon M. Outcome of snake bites in Al-Baha district. Annals of Saudi Medicine 1994;14:26-9.

5 Cockram CS, Chan JC, Chow KY. Bites by the white lipped pit viper and other species in Hong Kong: a survey of 4-years' experience at Prince of Wales Hospital. fournal of Tropical Medicine and Hygiene 1990;93:79-86.

6 Curries BJ, Sutherland SK, Hudson BJ, et al. An epidemiological study of snake bite envenomation in Papua New Guinea. Med 7 A A ust 1991;154:266-8.

7 Brain MJ, Vince JD. Treatment and outcome of venomous snake bite in children at Port Moresby General Hospital, Papua New Guinea. Transactions of the Royal Society of Tropical Medicine and Hygiene 1987;81:850-2.

8 Jamieson R, Pear NJ. An epidemiological and clinical study Jamieson R, Pear NJ. An epidemiological and clinical study
of snake-bites in children. Med $\mathcal{F}$ Aust 1989;150:698-702.

9 of snake-bites in children. Med f Aust 1989;150:698-702. Indian Pediatr 1991;28:731-5.

10 Tan KK, Choo KE, Ariffin WA. Snake bite in Kelantanese children: a five year experience. Toxicon 1990;28:225-30.

11 Fainaru M, Manny N, Hershko C, et al. Defibrination following Echis colorata bite in man. Isr $\mathcal{F}$ Med Sci 1970;6: $720-25$.

12 Mathai RP. Acute renal failure in children following snake bite. Ann Trop Paediatr 1981;1:73-6. 